\title{
Understanding Good Coping: A Submarine Crew Coping with Extreme Environmental Conditions
}

\author{
Shaul Kimhi \\ Department of Psychology, Tel Hai Academic College, Upper Galilee, Israel. \\ Email: shaul@shamir.org.il; shaulkim@adm.telhai.ac.il \\ Received September $5^{\text {th }}, 2011$; revised September $30^{\text {th }}, 2011$; accepted October $24^{\text {th }}, 2011$.
}

\begin{abstract}
The present study is based on in-depth interviews with 12 Israeli submarine crew members. The study examines various aspects of coping with submarine service and its unique characteristics from the crew members' points of view. Content analysis reveals the following salient themes: First, positive perception of submarine service: positive thinking, optimism and sense of humor, accompanied by cynicism. Second, the submarine team is characterized by high moral standards, high team spirit and a sense of the importance of the service. Third, social relationships are characterized by avoidance of conflicts, while maintaining a good atmosphere and high social cohesion. Fourth, crew members perceived separation from home, friends and daily life as the most difficult aspects to deal with. Fifth, they perceived the submarine as dangerous place but reduced aspects of danger by developing a sense of trust in their submarine and in their ability to control potential dangers. Study results are discussed in light of relevant theories. This study is unique in that it was a rare opportunity to get a glimpse into the unknown world of an Israeli submarine crew which is mostly secret and not open to researchers.
\end{abstract}

Keywords: Coping, Stress, Extreme Environment, Submarine Service, Positive Thinking, Optimism and Sense of Humor

\section{Introduction}

The present qualitative study is based on in-depth interviews with submarine crew members. The main objective of this study was to understand better good coping: How submarine crew which have gone through extensive selection and training, cope successfully with stressful condition. Furthermore, we wanted to examine, from the point of view of the crew members themselves, how they coped with the unique extreme environment (see definition below) of a submarine and to compare our results with other extreme environment research. The crew was asked questions about their experiences serving in a submarine. Overall, it was assumed that a submarine crew is a unique group of people who characterize by excellent coping abilities. Studying such group, which in most case is not exposed to the public, can teach us about characteristics of successful coping strategies with extreme stress, such as in the case of submarine service.

There has been a substantial increase in the number of people living and operating in isolated, confined, and artificially engineered environments, such as spacecraft, deep diving conditions, weather stations, submarines, and polar outposts (Sandal, 1998, 2000). These are often called "extreme environments" in the professional literature (e.g., Shimamiya et al., 2005; Steel, 2005). For example, according to Paulus et al., (2009) extreme environments are defined as an external context that exposes individuals to demanding psychological and/or physical conditions, and which may have profound effects on cognitive and behavioral performance. Coping with extreme environments requires the development of high physiological, psychological and social coping skills (Risberg et al., 2004; Sandal, 1998; Suedfeld \& Steel, 2000). Many factors may affect individual differences in coping successfully with extreme environment such as disruption of sleep-wake cycles, high workload, isolation, confinement, stress, and fatigue (Buguet, 2007; Cowings et al., 2007).

Not surprisingly candidates to serve in extreme environments go through different kinds of selection processes and intensive training to prepare them. Research has developed to improve the selection process (e.g., Walter, 1998; Gunderson \& Nelson, 1966). Extreme environment service requires various capabilities and coping strategies which enable the individual to deal successfully with the stressors typical to these environments (Sandal, 1999).

\section{Submarine as an Extreme Environment}

Submarine duty is widely recognized as one of the most stressful and psychologically demanding forms of military service. Salient stressors include an extremely small working and living space, absence of day/night cues, confinement, isolation from all interaction with the external world, monotony in routine, extended separation from family members, and prolonged and potentially dangerous operational responsibilities (Eid, 2002; Suedfeld \& Steel, 2000). In order to cope, submarine crew members must have great professional and technical knowledge and individual characteristics which promote performance under such circumstances (Sandal, 1999). In addition, they need to have the ability both for extensive teamwork under stress and for quick decision making (Espevik, Bjorn, Eid, \& Thayer, 2006). During periods at sea, the team has to work with full cooperation in order to fulfill the mission and to maintain a high safety level (Sandal et al., 1999). In their detailed literature review on capsule environments, Suedfeld and Steel (2000) presented four main potential sources of stress: physical stressors, psycho-environmental factors social factors and temporal factors: duration of the mission.

Submarine research is prominent in extreme environment research. This research may be grouped into four domains: 1) research focusing on personality characteristics, coping strategies and the inter-personal abilities of submarine crew members 
(Espevik et al., 2006; Sandal, 2003; 1999; Sandal et al., 1999). 2) research focusing on the stress situation, anxiety and other stress symptoms as a result of an emergency situation in a submarine. Some of this research has been done in simulators (Berg et al., 2005; Eid, 2004; 2002; Espevik et al., 2006; Slaven \& Windle, 1999; Van Wijk, 2001). 3) research focusing on physiological reactions as a result of stress situations during submarine missions and how these affect the human body (Cymerman et al., 2002; Risberg et al., 2004). 4) research focusing on the effect of submarine service on family members, like spouses (Synder, 1978). The first two groups of research are more relevant to the current study. However, unlike the current study, very few of the above studies were based on in-depth interviews with the submarine crew, describing their experiences from their own point of view.

Summing up the research, it may be claimed that submarine crews, like those in other capsule environments are in most cases characterized by very good coping abilities and high ability for team work including avoidance of conflicts. Moreover, longitudinal studies indicate that not only are crew members not negatively affected, but that their long range experiences are positive and strengthen them compared to their situations before the mission, and when measured against control groups (e.g., Palinkas, 1986; Suedfelf \& Steel, 2000). Based on the above studies and the salutogenic theory (Antonovsky, 1987), it was expected that our subjects would report high level coping ability which would be manifested as perception of service as highly challenging, denying feelings of danger and fears, would report good social relationships with colleagues, based on trust and conflict avoidance, and report job satisfaction.

\section{Coping with Stress}

Stress research has found that the ability to cope with prolonged stress situations depends, among others, on personality characteristics and coping strategies. Among the salient personal characteristics that have been identified as relating to good coping ability are: sense of coherence (Antonovsky, 1979) and hardiness (Kobasa, Maddi, \& Kahn, 1982; Maddi, 2006). In the present study, although the focus is not on personal characteristics, the sutdy's basic assumption is that, considering the selection process as well as the very extensive training, our participants are a unique group of people who display very good abilities to cope with the demands of an extreme environment like a submarine.

Three theories which provide a general model for coping with stress seem to be relevant to submarine service: 1) According to the cognitive appraisal theory (Lazarus \& Folkman, 1984; Folkman \& Lazarus, 1985), the impact of stress depends not only on the level of exposure to stress stimulus, but also on their perceived impact on individuals (Folkman, Lazarus, Gruen, \& Delongis, 1986). Accordingly it was expected that our submarine crew would appraise their job as only moderately dangerous and at the same time trust their ability to handle emergency situation. 2) Hobfoll's Conservation of Resources Theory (COR) claims that the impact of stress on a person depends, first of all, on threat or real loss of resources (Hobfoll, 2001). Overall, the balance between loss and gain of resources determines the effect of stress. Based on this theory our subjects were expected to report that they feel satisfaction and like their job and feel that the gains are higher than losses. 3) Theories which emphasize the connection between the ability to give and to get social support and coping ability with stress (e.g., Joseph, Yule, Williams, \& Andrews, 1993; Pierce, Sarason, \&
Sarason, 1996; Rees \& Freeman, 2009). It was assumed that crew member would report feelings of social support from their colleagues and mutual trust in each other. In addition, based on research that indicated the importance of sense of humor as an important tool in coping with stress situation (e.g., Abel, 2002; Abel \& Maxwell, 2002; Mauriello \& McConatha, 2007) it was expected that the subjects would report the use of much humor as part of daily routine during voyage mission.

\section{The Israeli Submarine}

The submarine which our subject served is a "Dolphin", operated by an electric-diesel engine. Dolphins are among the smallest submarines in the world. The submarine team are composed only of men. According to public sources (Wikipedia Dolphin, 2009; Wikipedia Israeli Navy, 2009; Defense industry daily, 2005) the crew includes 35 to 45 members who are grouped into six departments: machine; electricity and control; detection, navigation and communication; weaponry and sonar. In addition, there are a commander, a deputy commander and a cook. The submarine service is on a volunteer basis.

The current study examines various aspects of submarine crew coping from the salutogenic (Antonovsky, 1987) and positive (Seligman, 2003) points of view. The study tries to explore, from the crew's standpoint, what strategies are used to cope successfully with extreme environment such as submarine service. Due to the careful selection and long training, it was assumed that the submarine crew is composed of people with high ability to cope with stress situations.

\section{Research Hypotheses}

The research hypotheses have been formulated based on the literature review regarding coping with extreme environment and especially submarine as follows:

1) Crew members will perceive the submarine as a highly demanding and challenging.

2) Crew member will cope with fears and feelings of danger during the voyage by minimizing the level of danger on the one hand and by trusting their own abilities as well as those of their team as being capable of coping with the mission.

3) The main coping strategies will be based on sense of humor, positive thinking and optimism.

4) Social relationships among the crew will be based on trust, cooperation and conflict avoidance at all times.

\section{Method}

\section{Sample}

The sample consisted of 12 interviewees, among them officers of all ranks and noncommissioned (NCO) officers representing the six submarine departments. Each department was represented by an officer and a NCO. Due to earlier agreement with headquarter unit only a few biographic details were requested. Ages range from 20 to 40, most of the subjects had studied physics and/or computer orientation in high school. All subjects completed at least12 years of education and some have completed their higher education (one of them is an engineer). Most subjects grew up in big cities, some of them in small communities. Two were married, each with a child and most of the others had girlfriends but were not married.

\section{The Interview and Analysis}

The research tool was a structured interview constructed in 
several steps: First, based on research literature regarding submarines, the research goals were defined and accordingly, a first draft of the interview was prepared. Second, the interview was given to three submarine crew members for their comments. Following this, changes were made. Third, step two was repeated with another three crew members. At the end of this step, the final version was constructed as follows: each domain started with a general open question, followed by specific questions (only if the information was not given in reply to the general open question). In this way, we allowed the interviewees to respond in their own way, with a minimum of guidance from the interviewers.

Content analysis of interviews was done by attributing texts to content categories (e.g., Krippendorf, 1980; Jones et al., 2010). The process of building content categories was first based on the interview predetermined four general open questions: Submarine as an extreme environment, coping with fears and danger, coping strategies, social relationships and team work. These questions were selected based on the literature review. The process of attributing text to sub-categories (within each of the main four categories) was conducted as follows: The main researcher and two assistant researchers read the texts and attributed them independently to content categories. Comparison of content categories among the three researchers revealed high agreement of $85 \%$. All texts which indicated no agreement regarding their attribution to categories were brought to further discussion, and only if no agreement was reached (less than 3\%) another independent researcher was asked to decide. Based on our content analysis the main categories and sub-categories analyzed in this study were as follows: 1) A submarine as an extreme environment: separation, crowdedness and lack of privacy, routine and activity. 2) Coping with fears and feelings of danger: the submarine as a dangerous place, fears, talking about fears and danger. 3) Coping strategies: positive thinking and optimism, cynicism, humor and culture of "Palavra", night paper. 4) Social relationships and teamwork: social relations during voyages, ranks and military hierarchy.

The research started after getting permission from the unit headquarters. The interviews took place at the interviewee's home, after receiving their personal permission to be interviewed. At the beginning of each interview, it was clarified that the purpose of this study was to explore the personal experiences of submarine service. In addition, complete anonymity was assured. It is important to note that the interviewees displayed special interest in the research and were happy to cooperate. All interviews were recorded and transcribed word for word, excluding any possible identifying details.

\section{Analysis}

Analysis of results follows the content categories as presented above.

\section{Submarine as an Extreme Environment}

\section{Separation Experience}

There was clear agreement among participants that separation from home, family and friends is the most difficult aspect of submarine service. The following is an example:

NCO: "It is part of not knowing what is going on the outside; you are completely disconnected regarding telephones. Even news that you do get is very specific. I think that this is the most difficult experience. It is simply complete disconnection. For example, I had a long voyage and, at the time, my wife was pregnant. To see her all of a sudden after such a long time means that a lot of things have changed".

As mentioned above, separation from daily life, family and friends seems to be the most difficult part of the voyage. This is even truer if the person has a spouse and especially if he has children. It seems that some of the crew members cope with this difficulty mainly by trying to avoid thinking, and by concentrating on the mission as much as possible. Beyond the diverse responses, the salient one is that separation is a "great difficulty that one forced to live with".

\section{Crowdedness and Lack of Privacy}

As explained, Dolphin submarines are small and congested, and most of their space is used for operating systems. There is very little free space devoted to living conditions.

Officer: "Personally, congestion does not bother me, nor does lack of privacy; you have your own place. You have your bed, your own corner but, of course, it is small. Relatively, for a normal person, it might look crazy. It seems that everyone gets used to it quickly and to many other things. At the beginning, it really looks threatening, but very quickly it seems completely reasonable".

Our interviewees indicated that crowdedness was an integral part of life in a submarine and that they have learned and have even gotten used to living like that during a voyage. Most participants refer to their beds as the only private place in the submarine, and emphasize its importance: the ability to leave to your own private corner when you feel like it. The overall impression is that coping with crowdedness is perceived by the crew as trivial and understandable so that it almost does not bother them.

\section{The Voyage: Routine and Activity}

The following is an example how a crew member experience the long voyage and how he adjust to the changes going from routine and monotony to very hectic activity:

NCO: "Many times there are long voyages. There are difficulties in getting back to routine (afterward). The thoughts you have when you are in the submarine... There is this kind of difficulty that you are staying (in the sub) while everyone else (on land) continues with their lives. I think that there is another difficulty: As a department non-commissioned officer I have tremendous responsibilities which continue all the time. You know that you have responsibilities for many things all the time. This is a kind of difficulty".

Beyond the various responses regarding routine and activity, it seems that operational activity is the preferred way to make the time pass quickly, without having time for disturbing thoughts or feelings like yearning for home, boredom, separation etc.

The general impression is that crew responses support our first hypothesis: They perceive their service in a submarine as highly challenging environment but they do not refer to this environment as an extreme or even stressful one. Aside of mentioning lack of sleep, there were hardly any complaints regarding physical or psychological difficulties during a voyage. The conclusion might be that what seems as an extreme environment for an outside observer seems to the crew as a challenging but manageable routine.

\section{Coping with Fears and Danger}

\section{Submarine as a Dangerous Place}

This sub-category examined to what extent participants perceived their service in a submarine as a dangerous experience. 
The following is an example:

Officer: "Serving in a submarine is dangerous. Even in training, there are things that you wouldn't tell your mother. For example, we went through an escape course. Overall, I think that if you look at it seriously, not the way we look at it, it is usually dangerous".

The responses in regard to the submarine as a dangerous place were diversified: On the one hand, most participants agreed that a submarine is a dangerous place. On the other, most of them tended to minimize the level of danger. They tend not only to play down the danger, but also to balance it with a feeling of self-confidence in the vessel and in their ability to control potential risks. Sometimes there is also the sense that "there are things that you can do nothing about" or that risk is "something you have to learn to live with". It is kind of acceptance or "light fatalism". For example, at least one crew member mentioned the Dakar ${ }^{1}$ disaster, and claimed that somewhere, it is always in the back of his mind.

\section{Fears}

Participants were asked whether they have fears during voyages. Only a few related openly to fears. More participants replied that they do not have fears:

NCO: "Let's say that the longer you are in the submarine, the more you really understand how dangerous it is. At the beginning you sail and (you feel) it is not dangerous, here and there... but in time you really understand how every little thing can cause such great damage... But few people feel it. I, too, feel it less. If, for example, I was operating in the Gaza Strip with a small (commando) unit or something like that... Here you feel much more comfortable."

Among the various responses, it was obvious that senior and more experienced crew members were more willing to admit to the existence of dangers and were more willing to talk about fears. Evidently the most common strategy to cope with fears was developing a strong sense that there are professional people around you who can be trusted not to make mistakes operating the submarine systems. The most common response indicated that good training for various emergency situations enhanced feelings of security and safety. It is interesting to note that even those who denied having fears did not deny possible unexpected catastrophic events. At the same time, some of the crew members did not hesitate to express fears which accompany submarine service, openly and honestly.

\section{Talking about Fear and Danger}

In this sub-category we analyzed all texts which deals with the question whether crew members who live a life of teamwork so intensively talk to each other about their fears.

NCO: "Everyone has the same problem and "misery loves company'. It is good to know that I am not the only one. No talking about fears (since) this is not a matter of support. The support does not come from talking about it, but by finding ways to pass the time. We repress the problems, and overcome them. There is nothing to be done; you are there and that's it, so we try to pass the time together and with fun".

In accordance with our second hypothesis, crew members talk very little, if at all, about fears and dangers. It seems that there is silent agreement that discussing these subjects does not add to the ability to cope. This coping strategy may be defined as "rational denial", meaning: "we know that there are dangers

\footnotetext{
${ }^{1}$ An Israeli navy submarine that was lost in the Mediterranean in 1968 on its way from England to Israel. All 69 crew members on board were killed.
}

and fears, but to talk about them will not do any good”. Moreover, the overall impression regarding risks and fears revealed that crew members felt uneasy talking about these issues to the interviewer; there were hesitations, breaks in the middle of sentences, unfinished sentences and relatively less clear language. These results seem to support our second hypothesis indicating that feelings of danger during the voyage will be minimized.

\section{Coping Strategies}

\section{Positive Thinking and Optimism}

Interviews revealed clearly that crew members often used positive thinking during the voyage. Moreover, they focused on positive issues while negative ones were almost ignored (unless it was a professional issue). Crew members attributed more importance to the positive side of their work than to the negative.

NCO: "My work in the submarine fills me with energy no matter how hard and demanding the work is, no matter how many hours. When I come back home from a voyage, I return full of energy. I come back home after long voyage like I am floating on a cloud. This work gives me great satisfaction, it makes me happy. This is the work of a creator, a work of art".

Participants perceived their overall service as positive, meaningful and unique. It is not clear how much of this optimism and positive thinking developed during submarine service and how much existed prior to service. It seems that both are true: positive thinking exists prior to service and is further enhanced during service. Overall, interviews revealed a clearly positive attitude as a basic world perception, and specifically as a way to perceive submarine service.

\section{Cynicism, Humor and Culture of "Palavra"}

One of the most frequently used coping strategies was the culture of humor accompanied by cynicism, which developed among participants. As it turns out, this culture of humor is unique. It appears that those who are not part of the team might find it difficult to penetrate its nuances and connotations. For example:

Officer: "Due to cynicism you can say whatever you want and to whomever you want, without being told that you have really said something serious. Palavra is very important, it is team spirit. It is not exactly cynicism. There is cynicism in the submarine which has nothing to do with palavra. Cynicism is the weapon of divers. Using cynicism, you can say whatever you think without sounding as though you are rebuking anyone. Based on that principal, anyone can say anything about me. Everything is only palavra".

A possible example for palavra is the following: one day the cook prepared roles for the team and it got burn. Latter on a story spread among the team that one role fell from the table and the entire crew heard the "bang" noise when it hit the floor.

According to participants, they use their sense of humor, their cynicism and their palavra as part of coping with submarine life. Instead of conflict-which is so normal in every system where many people depend on each other without the option of choosing who to work with- there is a culture which allows for indirect expression of disagreements, anger, and frustration in a way that is approved of by all. Moreover, it seems that this culture is an old tradition which is passed down from generation to generation.

${ }^{2}$ Palavra means nonsense. In Spanish, the meaning is "word", and in Ladino, the local meaning developed: nonsense, stupidity, empty talk (Rosental, Maariv, 30-9-05). The English equivalent is "palaver". 
The high level of cynicism was not part of our hypotheses since- to the best of our knowledge- no other submarine research has indicated this before. However, in the case of the Israeli submarine crew the use of cynicism and ridicule on each other plays an important role as can shown in the case of night paper.

\section{Night Paper}

One of the unique crew expressions is the "night paper". It is a comic newspaper published every night and hung on the bulletin board for everybody to read. The paper is composed of magazine articles, journals, photos, and links. It is a unique instrument which allows review of the day's events harmoniously while using cynicism, mutual ridicule and language familiar to crew members. The following is an example:

NCO: "The night paper is our way of coping with painful things and expressing cynicism. It reflects cynicism. Instead of someone going and telling others (what he want to tell them), he just adds it to the night paper and that is how everybody knows about it. It is a funny and cynical paper that eases the routine, to create laughter".

An example could be a cartoon or fabricated picture of crew member who speaks loud as a famous opera singer or someone who had slipped on his way to the kitchen and later that day was presented on the night paper as an acrobat in the circus.

The night paper has the same purpose as humor and palavra: it enables the expression of different kinds of experiences, whether good or bad, while gently criticizing other person/s. Apparently, the night paper has become an accepted way to express feelings and thoughts without being insulting. These include criticism, humor, ridicule of others and of oneself, as well as of submarine life. Overall, the interviews reveal that, in accordance with our hypothesis, a sense of humor and optimism were salient coping strategies. In addition, somewhat unexpectedly, cynicism and mutual ridicule were also salient coping strategies of the submarine crew.

\section{Social Relationships and Team Work}

\section{Social Relationships during the Voyage}

During a voyage, the submarine is closed, isolated and disconnected from the outside world. Crew members cannot communicate with their families or friends. The only company they have is each other. As a result, there is no place for unnecessary disputes. A submarine crew, like other extreme environment crews, must maintain a good atmosphere in order to complete the mission.

Officer: "It happens that you have to work and share your life with a person whom you don't like. I try to retain professionalism and also to offer some kind of friendship. I am not a hypocrite; I will not tell this individual 'you are my best friend and I will do anything for you'. But I will be glad to do things for him".

Respondents indicated that there are good working relations and a positive social atmosphere. Yet this does not necessarily mean close or intimate relations after the voyage. Only a small number of friendships continue beyond that. It seems that social cohesion among the team is high, even though there are sub-groups. Evidently there is no social pressure to be friends with all the others.

\section{Ranks and Military Hierarchy}

A submarine is a unique military unit in the sense of military hierarchy. Although, like any army unit, there are ranks, the formal relations and distance among the crew members are different compared to other units in the Israeli Defense Forces (IDF). Crew members from all ranks and levels must live and work together very closely. The combination of submarine life and army ranking forces everyone to compromise.

Officer: "It is clear to everyone that an officer does not come and tell soldiers to do things only because he is an officer, but because there is something that has to be done. Many times we listen to soldiers, see if they have something better to suggest. It is not that something will happen because you, as an officer, change your mind".

The role of officers is, first of all, work distribution. Ranks represent operational authority, and to a lesser extent, command authority. A submarine captain is the only person on board whose rank is maintained: Crew members address him as "Hamefaked" (in Hebrew, the commander). From the various responses, it seems that the social interaction among crew members does not distinguish rank. The only place where there is a clear distinction according to rank is the "mess" (eating rooms). In accordance with our fourth hypothesis, social relationships are based very clearly on high trust and cooperation among the team members: It is clear that everyone will do his best to complete the mission perfectly. Many of the interviewers emphasized that they will avoid conflict with other colleagues even when there is disagreement and that it is very difficult to make them angry. The ways to handle such disagreements are night paper and "palavaras”.

\section{Discussion}

The most prominent results of the current study seem to be the positive perceptions of submarine service. These include positive thinking, optimism and humor accompanied by cynicism. Using positive thinking, optimism and humor are well known in professional literature as successful coping strategies with stress. These results are in accordance with research indicating that humor, positive attitudes and optimism reinforce resilience against the negative effects of distress (Abel \& Maxwell, 2002; Connor \& Zhang, 2006; Martinez, Reyes, Garcia, \& Gonzalez, 2006; Mauriello \& McConatha, 2007; Southwick, Vythilingam, \& Charney, 2005; Wooten, 1996).

It is possible to view the positive perception of submarine service by the submarine interviewee as corresponding to the salutogenic model research (e.g., Sagy \& Anotnovsky, 1986). This model research focuses on a self reported feeling of competence and satisfaction as a valid measure for successful coping with stress (e.g., Dar \& Kimhi, 2001, 2004). An additional way to explain the positive attitude to submarine demands by our subjects is by using cognitive appraisal theory (Lazarus \& Folkman, 1984). Accordingly, participants perceive their abilities as appropriate to cope with the submarine service demands. This perception helps them to feel that they can handle emergency situations and that these are challenging rather than dangerous. Nonetheless, this study cannot determine whether these means and mechanisms are unique to Israeli submarines only. More studies of how other navy crews form various cultures are needed to clarify this interesting point.

The current study indicated that one of the unique coping strategies used by the crew under study was the culture of "palavra" and the use of the "night paper" as a part of the subculture developed in the submarine. Apparently this strategy has a double goal: On the one hand, it is an efficient way to vent criticism and frustration which does not insult others bringing up the ridiculous and the absurd sides of submarine 
life and looking for a special point of view about submarine life in all its aspects. On the other, it prevents arguments, disagreements and conflicts in the congested working area, where conflicts and disagreements are undesirable and even dangerous. However, even though this was not said explicitly, it seems that these means are also used to ease worry and fear and to serve as "pressure release” mechanisms.

Regarding feelings of danger and fear, the current study indicated that crew members coped with these feelings by "diminishing” their perception of dangers and avoiding talk about fears among themselves. It is suggested to call this strategy an "optimal denial": On the one hand, they do not completely deny or ignore the danger. On the other, they do not live with a constant sense of risk that might interfere with their performance (see denial as a coping strategy in Breznitz, 1986). Additionally, crew member expressed high levels of confidence both with the submarine and in their ability to control most potential risks. These results support other studies according to which, expectation of being able to control the situation, characterized crew members coping successfully with extreme environments (e.g., Sandal et al., 1999; Levine \& Ursin, 1991).

Evidently, the need for extensive teamwork in a submarine, like other teams operating in extreme environments, requires a high ability for social relationships. This research clearly indicated the existence of teamwork, including social cohesion and good working relations without conflicts. Interestingly, good relationships crossed military hierarchy and rank. It appears that, unlike other military units, rank had mainly operational significance but much less social significance. Above all, it appears that submarine crews work harmoniously even though not everyone is a friend of everyone else. This harmony exists even if a person has to work with someone he does not like. The current study results support theories emphasizing personal ability for giving and receiving social support as a coping strategy with stress (Joseph, Yule, Williams, \& Andrews, 1993; Pierce, Sarason, \& Sarason, 1996; Rees \& Freeman, 2009). These results also support other submarine research using other methodologies which have indicated the importance of capability for social relationships as a necessary precondition for submarine service (Sandal et al., 1999; Sandal, 2003, 1999), and other studies regarding characteristics of submarine personnel (e.g., Wolfe, 1979).

Our research has indicated that high coping and performance under stress situations like extreme environments are connected with a personality profile which is characterized by high instrumentality and achievement, together with interpersonal sensitivity. Such a profile has been termed the "right stuff" in the literature, characterizing successful group coping with highly stressful situations (Sandal et al., 1999; Wolfe, 1979). The current results suggest adding to above profile the ability to avoid conflict as a very essential characteristic of good submarine crew member and probably a helpful feature for other crews operating in extreme environments.

Aside from separation difficulties, this study does not support some of the capsule research outcomes Suedfeld \& Steel (2000) emphasized social isolation, confinement and sensory restriction. In the interviews with the team in the current research, there were few reports of these difficulties. On the contrary, our subjects described feelings after a voyage as positive even though it had sometimes been very tough. Some of our results can be explained using Hobfoll's COR theory (2001): Crew members described the feeling of satisfaction they had at the end of the voyage at successfully having completed the mission and at their good functioning during the voyage. These descriptions match the explanation according to which gains of resources (like good feelings, satisfaction, and pride) overcome loss of resources (like separation). Moreover, in accordance with COR theory, respondents revealed the clear perception that, overall, submarine service involved more gain than loss of resources.

Beyond our specific hypotheses additional results indicated high morale, team spirit and values. These included-among others - wide agreement concerning the importance of the submarine and its missions and high unit pride. There is consensus among experts that these psycho/social components are very important in every combat unit and that their importance does not diminish even though the weapons become more and more sophisticated. For example, Holmes (1989) emphasizes the importance of the moral qualities of the combat soldier. According to him, even the most modern weapons systems are limited and depend on the soldiers who operate them. In the end, the soldier's values are basic and most important in every combat unit (see also Griffith, 1988; Kimhi \& Sagy, 2008).

\section{Limitations of the Study}

Like any other research, this one also has limitations:1) the small number of interviewees requires caution regarding generalization about Israeli submarine crews and does not allow for generalization to crew members from other navies, 2) difficulties in comparing the current study with other submarine studies using mainly quantitative methodology, 3) some caution should be applied regarding the possibility that significant experiences (e.g., risks, fears) took place during classified missions and, as a result, did not come up during the interviews.

\section{Conclusion}

What is the main pragmatic conclusion from our study? In essence, it is possible to claim that this study clearly indicates the importance of the human factor in one of the most modern sophisticated war machines such as the submarine: There is no substitute for the crew members operating this system, team spirit, values, and ability for team work and positive attitudes to mission demands (see also Holmes, 1989). These are domains which can be fostered and encouraged in any team and certainly in elite teams such as those on submarines which have been selected after strict processes, and long and extensive training.

\section{References}

Abel, M. H. (2002). Humor, stress and coping strategies. Humor: International Journal of Humor Research, 15, 365-377. doi:10.1515/humr.15.4.365

Abel, M.H., \& Maxwell, D. (2002). Humor and effective consequences of a stressful task. Journal of Social and Clinical Psychology, 21, 165-190. doi:10.1521/jscp.21.2.165.22516

Antonovsky, A. (1987). Unraveling the mystery of health. San Francisco: Jossey-Bass.

Antonovsky, A. (1979). Health, stress and coping: New perspectives on mental and physical well-being. San Francisco: Jossey-Bass.

Berg, J. S., Grieger, T. A., \& Spira, J. L. (2005). Psychiatric symptoms and cognitive appraisal following the near sinking of a research submarine. Military Medicine, 170, 44-47.

Breznitz, S. (1986). Are there coping strategies? In S. McHugh, \& T. M. Vallis (Eds.), Illness behavior: A multidisciplinary model (pp. 325-329). New York, NY: Plenum Press

Buguet, A. (2007). Sleep under extreme environments: Effects of heat 
and cold exposure, altitude, hyperbaric pressure and microgravity in space. Journal of the Neurological Sciences, 262, 145-152.

doi:10.1016/j.jns.2007.06.040

Connor, K. M., \& Zhang, W. (2006). Resilience: Determinants, measurement, and treatment responsiveness. CNS Spectrums, 11, 5-12.

Cowings P., Toscano, W., De roshia, C., Taylor, B., Hines, A., Bright, A., \& Dodds, A. (2007). Converging indicators for assessing individual differences in adaptation to extreme environments. Aviation, Space and Environmental Medicine, 78, 195-215.

Cymerman, A., Young, A. J., Francis, T. J., Wray, D. D., Ditzler, D. T., Stulz, D., Bovill, M., \& Muza, S. R. (2002). Subjective symptoms and postural control during a disabled submarine simulation. Undersea and Hyperbaric Medicine, 29, 204-215.

Dar, Y., \& Kimhi, S. (2004). Youth in the military: Gendered experiences in the conscript service in the Israeli Army. Armed Forces and Society, 30, 433-459. doi:10.1177/0095327X0403000306

Dar, Y., \& Kimhi, S. (2001). Military service and self-perceived maturation among Israeli youth. Journal of Youth and Adolescence, 30, 427-448. doi:10.1023/A:1010493116011

Defense Industry Daily (15 October 2007). Germany may sell 2 more Dolphin sub to Israel for 1.17B\$. URL (last checked 15 October 2007)

http://www.defenseindustrydaily.com/germany-may-sell-2-more-dol phin-subs-to-israel-for-117b-01528/

Eid, J. (2002). Acute stress reactions after submarine accidents. Journal of Military Medicine, 167, 427-431.

Eid, J. (2004). Stress and coping in a week-long disabled submarine exercise. Aviation, Space and Environmental Medicine, 75, 616-621.

Espevik, R., Bjorn, H. J., Eid, J., \& Thayer, J. F. (2006). Shared mental models and operational effectiveness: Effects on performance and team processes in submarine attack teams. Military Psychology, 18, 23-36. doi:10.1207/s15327876mp1803s_3

Folkman, S., \& Lazarus, R. S. (1985). If it changes it must be a process: Study of emotion and coping during three stages of a college examination. Journal of Personality and Social Psychology, 48, 150-170. doi:10.1037/0022-3514.48.1.150

Folkman, S., Lazarus, R. S., Gruen, R. J., \& Delongis, A. (1986). Appraisal, coping, health status, and psychological symptoms. Journal of Personality and Social Psychology, 50, 571-579. doi:10.1037/0022-3514.50.3.571

Griffith, J. (1988). Measurement of group cohesion in US army units. Basic and Applied Social Psychology, 9, 149-171. doi:10.1207/s15324834basp0902 6

Gunderson, E. K., \& Nelson, P. D. (1966). Criterion measures for extremely isolated groups. Personnel Psychology, 19, 67-81. doi:10.1111/j.1744-6570.1966.tb02436.x

Hobfoll, S. E. (2001). The influence of culture, community, and the nested-self in the stress process: Advancing conservation of resources theory. Applied Psychology: An International Review, 50, 337-421. doi:10.1111/1464-0597.00062

Holmes, R. (1989). Acts of war: The behavior of men in battle. New York: Free Press.

Jones, D. K., Evenson, K. R., Rodriguez, D. A., \& Aytur, S. A. (2010). Addressing pedestrian safety: A content analysis of pedestrian master plans in North Carolina. Traffic Injury Prevention, 11, 57-65. doi:10.1080/15389580903434199

Joseph, S., Yule, W., Williams, R., \& Andrews, B. (1993). Crisis support in the aftermath of disaster: A longitudinal perspective. British Journal of Clinical Psychology, 32, 177-185. doi:10.1111/j.2044-8260.1993.tb01042.x

Kimhi, S., \& Sagy, S. (2008). Moral justification and feeling of adjustment to military law-enforcement situations: Israeli soldiers serving at army roadblocks. Mind and Society, 7, 177-191. doi:10.1007/s11299-008-0051-0

Kobasa, S. C., Maddi, S. R., \& Kahn, S. (1982). Hardiness and health: A prospective study. Journal of Personality and Social Psychology, 42, 168-177. doi:10.1037/0022-3514.42.1.168

Krippendorf, K. (1980). Content analysis: An introduction to its methodology. Beverly Hills, CA: Sage

Lazarus, R S., \& Folkman, S. (1984). Stress, appraisal and coping. New York: Springer.

Levine, S., \& Ursin, H. (1991). What is stress? In M. R. Brown, G. F. Koob, \& C. Rivier (Eds.), Stress-Neurobiology and neuroendocri- nology. New York: Marcel Dekker

Maddi, S. R. (2006) Hardiness: The courage to grow from stresses. Journal of Positive Psychology, 1, 160-168. doi:10.1080/17439760600619609

Martínez-Correa, A., Reyes del Paso, G. A., García-León, A., \& González-Jareño, M. I. (2006). Relationship between dispositional optimism/pessimism and stress coping Strategies. Psicothema, 18, 66-72.

Mauriello, M., \& McCopnatha, J. T. (2007). Relations of humor with perceptions of stress. Psychological Reports, 101, 1057-1066.

Palinkas, L. A. (1986). Health and performance of antarctic winter-over personnel: A follow up study. Aviation, Space, and Environmental Medicine, 57, 549-559.

Pierce, G. R., Sarason, B. R., \& Sarason, I. G. (1996). Handbook of social support and the family. New York, NY: Plenum Press

Paulus, M. P., Potterat, E. G., Taylor, M. K., Van Orden, K. F., Bauman, J., Nomen, N., Padills, G. A., \& Swain, J. L. (2009). Neuroscience approach to optimizing brain resources for human performance in extreme environments. Neurosciences and Biobehavioral Reviews, 33, 1080-1088. doi:10.1016/j.neubiorev.2009.05.003

Rees, T., \& Freeman, P. (2009). Social support moderates the relationship between stressors and task performance yhrough delf-rfficacy. Journal of Social and Clinical Psychology, 28, 244-263. doi:10.1521/jscp.2009.28.2.244

Risberg, J., Ostberg, C., Svensson, T., Norfleet, W., Ornhage, H., Mjaavatten, O., \& Juvik, T. (2004). Atmospheric changes and physiological responses during a 6-day "disabled submarine" exercise. Aviation, Space, and Environmental Medicine, 75, 138-149.

Sagy, S., \& Antonovsky, A. (1986). Adolescents reaction to the evacuation of the Sinai settlements: A longitudinal study. The Journal of Psychology, 120, 543-556.

doi:10.1080/00223980.1986.9915485

Sandal, G. M. (1998). The effects of personality and interpersonal relations on crew performance during space simulation studies. Life Support and Biosphere Science: International Journal of Earth Space, 5, 461-470.

Sandal, G. M. (1999). The effects of personality and interpersonal relations on crew performance during space simulation studies. $\mathrm{Hu}$ man Performance in Extreme Environments, 4, 43-50.

Sandal, G. M. (2000). Coping in Antarctica: Is it possible to generalize results across settings? Aviation, Space and Environmental Medicine, $71,37-43$.

Sandal, G. M. (2003). Personality and coping strategies during submarine missions. Human Performance in Extreme Environments, 7, $29-42$.

Sandal, G. M., Endresen, I. M., Vaernes, R., \& Ursin, H. (1999). Personality and coping strategies during submarine missions. Military Psychology, 11, 381-404. doi:10.1207/s15327876mp1104_3

Seligman, M. E. P. (2003). Positive psychology: Fundamental assumptions. The Psychologist, 16, 126-127.

Shimamiya, T., Terada, N., Wakabayashi, S., \& Mohri, M. (2005). Mood change and immune status of human subjects in a 10-Day confinement study. Aviation, Space, and Environmental Medicine, 76, 481-485.

Slaven, G. M., \& Windle, C. M. (1999). Cognitive performance over 7 days in distressed submarine. Aviation, Space, and Environmental Medicine, 70, 604-608.

Southwick, S. M., Vythilingam, M., \& Charney, D. S. (2005). The psychobiology of fepression and tesilience to dtress: Implications for prevention and treatment. Annual Review of Clinical Psychology, 1, 255-291. doi:10.1146/annurev.clinpsy.1.102803.143948

Steel, G. D. (2005). Whole lot of parts: Stress in extreme environments. Aviation, Space, and Environmental Medicine, 76, 67-73.

Sturgeon, J. (2007). The psychology of isolation. URL (last checked 28 February 2007) http://www.space.edu/libraryResearch/undgrant.html

Suedfeld, P., \& Steel, J. D. (2000). The environmental psychology of capsule habitats. Annual Review of Psychology, 51, 227-253. doi:10.1146/annurev.psych.51.1.227

Synder, A. I. (1978). Sea and shore rotation: The family and separation: Phase II final report. US Department of Defense. Blacksburg, VA: Technical Information Center.

Van Wijk, C. (2001). Submarine escape: The effect of training on anxiety. Journal of Human Performance in Extreme Environments, 5, 7-10. 
Walter, P. H. (1998). The selection of submarine commanding officers: Leadership in an extreme environment. Human Performance in EXtreme Environments, 3, 13-25.

Wikipedia-Dolphin class submarine. URL (last checked 9 March 2009) http://en.wikipedia.org/wiki/Dolphin_submarine
Wikipedia-Israeli navy. URL (last checked 9 March 2009) http://en.wikipedia.org/wiki/Israeli_navy.

Wolfe, T. (1979). The right stuff. New York: Farrar, Straus \& Giroux. Wooten, P. (1996). Humor: An antidote for stress. Holistic Nursing Practice, 10, 49-56. 